Original article

\title{
Is Haemophilus influenzae better satellite for Enterococcus faecalis?
}

\author{
Firat Zafer Mengeloglu, Tekin Tas, Esra Kocoglu, Özlem Bucak, Seyda Karabörk, Kübra Ceylan
}

Abant Izzet Baysal University, Bolu, Turkey

Received 12 July 2013, Accepted 25 July 2013

(C) 2013, Mengeloglu F.Z., Tas T., Kocoglu E., Bucak Ö., Karabörk S., Ceylan K.

(C) 2013, Russian Open Medical Journal

\begin{abstract}
Background - Haemophilus influenzae can grow on blood agar media with Staphylococcus aureus which can provide factor $\mathrm{V}$ as it is called "Satellite phenomenon". Objectives - In this study we tested and compared three different beta-haemolytic genus including three Staphylococcus aureus, three coagulase-negative staphylococci, and two Enterococcus faecalis strains in order to determine an alternative microorganism to be used for satellite test to identify $\mathrm{H}$. influenzae conventionally. Materials and Methods - We used suspensions of $H$. influenzae in two different tribudities as 0.5 and 4 McFarland for each strain. Five totally-blinded reviewers examined the test results and scored both the colony sizes of $H$. influenzae and the diameter of the growth-zone. The sum of the scores for the colony sizes and the growth-zones were determined as "total diagnostic score" (TDS) as being between 0-6 points for each test. Results - A total of 320 test scores were analysed. The mean TDS of $E$. faecalis group was significantly higher than the other groups ( $p<0.001$ ). In the S. aureus group, $23(19.2 \%)$ tests had 0 points as TDS; but in enterococci group no isolates had lower scores than 3 points. In enterococci group, the rate of isolates which had 5 or 6 points was $77.5 \%$ (62/80); but in S. aureus group no isolate had higher than 4 points. Conclusions - Our study shows that using a beta-haemolytic E. faecalis strain will provide significantly more accurate results and will significantly reduce false-negative results for satellite test instead of $S$. aureus, which is particularly proposed to be used.
\end{abstract}

Keywords: Haemophilus influenzae, satellite phenomenon, satellite test, Enterococcus faecalis

Cite as Mengeloglu FZ, Tas T, Kocoglu E, Bucak O, Karabork S, Ceylan K. Is Haemophilus influenzae better satellite for Enterococcus faecalis? Russian Open Medical Journal 2013; 2: 0302.

Correspondence to Firat Zafer Mengeloglu. Address: Abant Izzet Baysal University, Faculty of Medicine, Department of Medical Microbiology, 14280 Bolu, Turkey. Tel: +90 3742534656 / 3264. Fax: +90 374 2534559. E-mail: mengeloglu@gmail.com

\section{Introduction}

Haemophilus influenzae is a non-motile and non-spore-forming gram-negative coccobacillus and can lead sinusitis, otitis, conjunctivitis and meningitis as well as upper and lower respiratory tract infections [1-4].

$H$. influenzae needs factor $\mathrm{X}$ (Hemin) and factor $\mathrm{V}$ (Nicotin adenin dinucleotide) for growing of in laboratory conditions [2]. $H$. influenzae can grow on chocolate agar plate prepared with heat-lysed horse blood or rabbit blood, or on blood agar media with some bacteria such as Staphylococcus aureus, coagulasenegative staphylococci (CNS) or enterococci which are capable of beta-haemolysis and which can provide factor $\mathrm{V}$; this cooperation is called "Satellite phenomenon" $[1,2,5]$. In the guidelines, the standard strain of S. aureus ATCC 25923 is proposed to be used for satellite test in order to identify the haemophilus-like colony as a conventional method in lack of factor $\mathrm{X}, \mathrm{V}$ or $\mathrm{XV}$ discs $[1,2,5]$.

In this study, it was aimed to test and compare betahaemolytic bacteria for conventional identification of H. influenzae.

\section{Materials and Methods}

\section{Bacterial isolates}

In the study, two different $H$. influenzae strains isolated from clinical specimens and identificated with API NH (BioMeriéux, France) and three S. aureus (Including S. aureus ATCC 25923), three CNS, and two Enterococcus faecalis strains all of which are beta-haemolytic isolates obtained from clinical specimens were used for satellite tests.

\section{Satelite tests}

To provide an objective and standard examination, $H$. influenzae strains were suspended in both 0.5 and 4 McFarland tribudity and inoculated onto blood agar media in duplicates. Paper discs in $6 \mathrm{~mm}$ in-diameter were placed onto the media in order to standardize the colony sizes of the test bacteria by absorbing the suspensions. Each of the test bacteria was suspended in $1 \mathrm{McF}$ arland and $5 \mu \mathrm{L}$ of each was added onto the discs. As a result, it was provided that each $H$. influenzae strain was tested for a total of four times with each beta-haemolytic strain. The media were incubated at $37^{\circ} \mathrm{C}$ in $\mathrm{CO}_{2}$-enriched incubator for $24 \mathrm{~h}$. 


\section{Reviewers}

At the end of incubation, the examinations were done by five reviewers constituting of two microbiology specialists, two research assistants and one master student all of that were experienced in microbiology for at least two years. The media cultures were examined by the reviewers for satellite tests as totally blinded of the row of the test bacteria and of the other reviewers' test results.

\section{Scoring}

For each satellite test, the reviewers scored both the colony sizes of $H$. influenzae and the diameter of the growth-zone. The scores were determined as 0 (No growth), 1 (Low), 2 (Media) and 3 (High). The sum of the scores for the colony sizes and the growthzones were determined as "total diagnostic score" (TDS). As a summary, each reviewer scored as a total of 64 satellite tests constituting of two $H$. influenzae strains in two distinct densities and in duplicates for 8 test bacteria.

\section{Statistical analysis}

Descriptive variables were presented as numbers and percentages and diagnostic scores were expressed as mean \pm standard deviation (SD).

An independent sample $T$ test or a Mann-Whitney $U$ test was used for comparison between the two groups. An independent sample $T$ test or a Mann-Whitney $U$ test was used for comparison between the two groups, and analysis of variance test was used for comparison amongst all groups. The results were interpreted within a confidence interval of $95 \%$, and a $p$ value of $<0.05$ was considered as significant.

\section{Results}

At the end of the test, a total of 320 test scores of five reviewers were analysed. The mean total diagnostic score (MTDS) of $S$. aureus ATCC 25923 strain was $2.20 \pm 0.99$. MDSs of the groups of $S$. aureus and E. faecalis were $2.01 \pm 0.97$ and $5.38 \pm 0.95$, respectively (Table 1$)$. The MTDS of $E$. faecalis group was significantly higher than MTDS of $S$. aureus $(p<0.001)$. MTDS of enterococci was also significantly higher than the other groups $(p<0.001$ for all). No significant difference was found between the scores of $\mathrm{S}$. aureus and CNS groups ( $p>0.05)$ (Table 1 ).

In the S. aureus group, $23(19.2 \%)$ tests had 0 points as TDS; but in enterococci group no isolates had lower scores than 3 points. In enterococci group, the rate of isolates which had 5 or 6 points was $77.5 \%$ (62/80); but in $S$. aureus group no isolate had higher than 4 points (Table 2 ).

\section{Discussion}

Despite latex particle agglutination test (LAT) or polymerase chain reaction (PCR) assay are more sensitive methods than culture to detect $H$. influenzae, they are not widely used routinely in clinical settings $[6,7]$. However, antibiotic susceptibility testing is not possible with LAT or PCR alone, so a parallel culture is necessary for large-sized laboratories $[6,7]$.

Culture of $\mathrm{H}$. influenzae is not highly sensitive due to antibiotic use prior to sample collection, poor collection or transport techniques or poor examination of culture by low-experienced technicians $[6,8]$. For these reasons, culture examination or conventional test methods for isolation of $H$. influenzae, importance of diagnosis increases particulary for small-sized laboratories $[6,8]$.

In the early $20^{\text {th }}$ century, the "satellite test" was found for presumptive laboratory diagnosis of $H$. influenzae and this test has been accepted as a conventional method for about a hundred years $[1,2]$. Satellite test shows the dependence of the isolate to factor $X$ and $V$ for growing $[1,2]$. Factor $X$ and $V$ dependence is needed to be tested for most clinical specimens $[9,10]$. Guidelines state that a beta-haemolytic $S$. aureus strain is needed to be used in the test $[2,5]$. However, some species of beta-haemolytic microorganisms other than $S$. aureus may provide positive results when tested with a heamophilus-like suspected-colony [2]. The question is, which bacteria can be the best for accurate identification.

Table 1. Mean total diagnostic scores (MTDS) of the isolate groups used in the satellite test

\begin{tabular}{lcc}
\hline \multicolumn{1}{c}{ Isolate group } & MTDS* & SD** \\
\hline S. aureus ATCC 25923 strain & 2.20 & 0.992 \\
S. aureus group (All) & 2.01 & 0.974 \\
CNS** group & 2.53 & 1.409 \\
E. faecalis group & 5.38 & 0.946 \\
\hline
\end{tabular}

*MTDS calculated by addition of the points of colony size and growth-zone scored by the reviewers

**Coagulase-negative staphylococci

Table 2. Distribution of the number of isolates according to "Total diagnostic scores"

\begin{tabular}{lccccccc}
\hline \multirow{2}{*}{ Isolate groups } & & \multicolumn{5}{c}{ Total diagnostic scores (TDS) } \\
& of tests & 0-1 points & 2-4 points & 5-6 points \\
\cline { 2 - 8 } & 120 & 23 & 19.2 & 97 & 80.8 & 0 & 0 \\
\hline S. aureus group & 120 & 20 & 16.7 & 90 & 75.0 & 10 & 8.3 \\
CNS* group & 80 & 0 & 0 & 18 & 12.0 & 62 & 41.3 \\
E. faecalis group & 120 &
\end{tabular}

*Coagulase-negative staphylococci

Centers for Disease Control and Prevention advise S. aureus or enterococci to be used in satellite test but in our study enterococci was shown to be better to be preferred [5].

In this study, we have found that beta-haemolytic $E$. faecalis strains showed significantly more accurate results among all tested isolates as well as $S$. aureus. E. faecalis strains had significantly higher mean diagnostic scores as well as none of those caused false-negative results.

\section{Conclusion}

Our study shows that using a beta-haemolytic E. faecalis strain will provide significantly more accurate results and will significantly reduce false-negative results for satellite test instead of $S$. aureus, which is particularly suggested to be used. According to our results, we consider that $H$. influenzae will be a "better satellite" for beta-haemolytic E. faecalis.

\section{Acknowledgements}

As the authors, we would like to thank Aysun Özüdogru, a specialist of English literature, for her help in redaction of our manuscript.

Conflict of interest: none declared. 


\section{Reference}

1. Campos JM. Haemophilus. In: Manual of clinical microbiology, 7th ed. Murrray PR, Baron EJ, Pfaller MA, Tenover FC, Yolken RH, eds. American Society for Microbiology, Washington DC, USA, 1999: 604613.

2. York $M$, Traylor $M$, Hardy J, Henry M. Biochemical tests for the identification of aerobic bacteria. In: Clinical Microbiology Procedures Handbook. 2nd ed. ASM Press, Washington DC, USA, 2007: 3.17.44.13.

3. Pasteurellaceae: Biology, Genomics and Molecular Aspects. Kuhnert $P$, Christensen H, eds. Caister Academic Press, Norfolk, UK, 2008: 27-51.

4. Ryan KJ. Haemophilus and Bordetella. In: Sherris Medical Microbiology 4th ed. Ryan KJ; Ray CG, eds. Medical Publishing Division, McGraw-Hill, USA, 2004: 396-401.

5. Centers for Disease Control and Prevention (CDC). Manual for the Laboratory Identification and Antimicrobial Susceptibility Testing of Bacterial Pathogens of Public Health Importance in the Developing World. Geneva, Switzerland, 2002: 5-15.

6. Kennedy WA, Chang SJ, Purdy K, LE T, Kilgore PE, Kim JS, et al. Incidence of bacterial meningitis in Asia using enhanced CSF testing: polymerase chain reaction, latex agglutination and culture. Epidemiol Infect 2007; 135 (7): 1217-1226. (doi: 10.1017/S0950268806007734) (PMCID: PMC2870670) (PMID: 17274856)

7. Kilian M. Genus III. Haemophilus Winslow, Broadhurst, Buchanan, Krumwiede, Rogers and Smith. In: Bergey's Manual of Systematic Bacteriology. Garrity GM, eds. Springer-Verlag, New York, USA, 2005: 883-904.

8. John TJ, Cherian T, Steinhoff MC, Simoes EA, John M. Etiology of acute respiratory infections in children in tropical southern India. Rev Infect Dis 1991; 13, Suppl 6: S, 463-469. (PMID: 1862277)

9. Sandstedt SA, Zhang L, Patel M, McCrea KW, Qin Z, Marrs CF, et al. Comparison of laboratory-based and phylogenetic methods to distinguish between Haemophilus influenzae and $\mathrm{H}$. haemolyticus. $J$ Microbiol Methods 2008; 75(2): 369-371. (PMID: 18652852) (doi: 10.1016/j.mimet.2008.06.023) (PMCID: PMC2603470)

10. McCrea KW, Xie J, LaCross N, Patel M, Mukundan D, Murphy TF, et al. Relationships of nontypeable Haemophilus influenzae strains to hemolytic and nonhemolytic Haemophilus haemolyticus strains. J Clin Microbiol 2008; 46: 406-416. (doi: 10.1128/JCM.01832-07) (PMID: 18039799) (PMCID: PMC2238123)

\section{Authors:}

Firat Zafer Mengeloglu - MD, Assistant Professor, Department of Medical Microbiology, Faculty of Medicine, Abant Izzet Baysal University, Bolu, Turkey;

Tekin Tas - MD, Assistant Professor, Department of Medical Microbiology, Faculty of Medicine, Abant Izzet Baysal University, Bolu, Turkey;

Esra Kocoglu - MD, Associate Professor, Department of Medical Microbiology, Faculty of Medicine, Abant Izzet Baysal University, Bolu, Turkey;

Özlem Bucak - MD, Research Assistant, Department of Medical Microbiology, Faculty of Medicine, Abant Izzet Baysal University, Bolu, Turkey;

Seyda Karabork - Biology Specialist, Department of Medical Microbiology, Faculty of Medicine, Abant Izzet Baysal University, Bolu, Turkey;

Kubra Ceylan - Biologist, Department of Medical Microbiology, Faculty of Medicine, Abant Izzet Baysal University, Bolu, Turkey. 